${ }^{1}$ Dr. Mohammed Mustafizur Rahman Assistant Professor Dept. of Pathology Popular Medical College (PMC)

${ }^{2}$ Dr. Shabnam Imam Assistant Professor Dept. of Community Medicine Bangladesh Medical College Hospital

${ }^{3}$ Dr. Mst. Sayedatun Nessa Assistant professor Dept. of Pathology Northern International Medical College, Dhaka

${ }^{4}$ Dr. Joyosree Saha Assistant Professor Dept. of Obs \& Gynae PMC

${ }^{5}$ Dr. Farhana Islam Assistant Professor Dept. of Pathology PMC

${ }^{6}$ Dr. Abu Khalid Muhammad Maruf Raza Assistant Professor Dept. of Pathology Jahurul Islam Medical College Bajitpur, Bangladesh

\section{Correspondence}

Dr. Mohammed Mustafizur Rahman Assistant Professor Dept. of Pathology Popular Medical College, Dhaka. e-mail: dr_amsm@yahoo.com

\title{
Pap smear in women with leucorrhea : Experience in a tertiary medical college hospital of Bangladesh
}

\author{
M Rahman ${ }^{1}$, S Imam², S Nessa ${ }^{3}$, J Saha ${ }^{4}$, F Islam ${ }^{5}$, A K M M Raza ${ }^{6}$
}

Abstract

Background : Poor genital hygiene has been responsible for high prevalence of excessive vaginal discharge. Leucorrhoea is the clinical evidence of infection and can be treated satisfactorily whenever diagnosed. Occurrence of various cervical epithelial lesion associated with discharge can be easily prevented if detected early. Majority of the patients with various cervical epithelial lesion attending in the hospital present with varying degree of vaginal discharge and cytological cellular aberrations in the cervical epithelium.

Objective : The aim of the present study is to observe the various patterns of cervical epithelial lesions in cytopathology and associated infections in patients with Leucorrhoea.

Methodology : This observational study was done over a period of ten months in Popular Medical college hospitals of Bangladesh. A total of 230 cases were included in the study with women of age range 15-45 years, complaining of leucorrhoea. After a thorough vaginal examination Pap smears were taken and immediately fixed in absolute alcohol and stained according to the papanicolaous technique. The cytopathological changes observed in the cervical smears were graded according to the Bethesda system for reporting cervical cytology.

Results : Out of 230 cases the cytological patterns were found Normal in $4(1.7 \%)$, Inflammatory $204(88.3 \%)$, Low grade squamous intraepithelial (LSIL)10 (4.8\%), High grade squamous intraepithelial (HSIL) 6(2.6\%), Atypical squamous cells of undetermined significance (ASCUS) $6(2.6 \%)$ and the distribution of different types of pathogens detected were Trichomonas 33 (70.62\%), Candida albicans 19 (40.66\%).

Conclusion : In this study significant numbers of Leucorrhoea patients were detected with cervical squamous intraepithelial lesions (SIL) in which LSIL (Low grade squamous intraepithelial) was higher. Associated infections were Trichomonas and Candida albicans. Therefore cytological screening for early detection of cervical squamous intraepithelial lesion is essential routine medical examination for Leucorrhoea patients in gynaecological practice.

Keywords : Leucorrhoea, squamous intraepithelial lesions (SIL), cervical cytology, Bethesda system.

DOI: http://dx.doi.org/10.3329/nimcj.v9i1.35921

Northern International Medical College Journal Vol. 9 No. 1 July 2017, Page 252-254

\section{Introduction}

Poor genital hygiene of women has been responsible for high prevalence of excessive vaginal discharge ${ }^{1}$. Leucorrhoea is the clinical evidence of infection and can be treated satisfactorily whenever diagnosed. Majority of cancer patients attending in the hospital present with varying degree of vaginal discharge and cytological monitoring of these subjects is mandatory to know any cellular aberrations in the cervical epithelium as well as the presence of any sexually transmitted diseases (STD's) in the genital tract. Cervical cancer is the fourth most common cancer affecting women worldwide, after breast, colorectal and lung cancers. ${ }^{2}$ Cervical cancer is the 12 th most common cancer among females in the U.K (2011), accounting for around $2 \%$ of all new cases of cancer in females ${ }^{2,3}$. However in the past 40 years, the number of cases and the number of deaths from cervical cancer have decreased significantly ${ }^{4}$. This decline largely is the result of many women getting regular Pap tests, which can find cervical precancer before it turns into cancer ${ }^{5}$.

Thus cytological screening (cervical cytology and Papanicolaous stain) should gain much popularity and should be accessible to all to identify the various lesions of cervix in women complaining of leucorrhoea and main emphasis to be given on the precancerous lesions of 
cervix. Cytological evaluation of cervical smears has been carried out in 230 women attending in Gynaecology O.P.D at Popular medical College hospital with complaint of vaginal discharge. This study was done to observe the incidence of cervical epithelial lesion in cytopathology and associated infections in patients with Leucorrhoea.

\section{Material and Methods}

This observational study was done over a period of ten months in Popular Medical college hospitals of Bangladesh.The present study included 230 women who came with the complaint of vaginal discharge with the age ranging from $15-45$ years, complaining of leucorrhoea. Cervix as visualized with Sim's speculum. After a thorough vaginal examination Pap smears were taken by ayre's spatula. Smears were immediately fixed in absolute alcohol and stained according to the papanicolaous technique. The cytopathological changes observed in the cervical squamous epithelial cells were graded according to the Bethesda system for reporting cervical cytology. ${ }^{5}$

Criteria of Bethesda system includes: Specimen adequacy, general categorization, negative for intraepithelial lesion, organisms, other non-neoplastic findings, epithelial cell abnormalities (ASCUS, LSIL, HSIL, SCC) and glandular cell abnormalities.

\section{Observations and Results}

Cytological pattern observed Among 230 cases. Cytological pattern was found as Normal in $4(1.7 \%)$, Inflammatory-204 $(88.3 \%)$, cervical squamous intra epithelial lesions (SIL) were seen in 22 cases (10\%). Cervical squamous intraepithelial lesion were distributed as 10 cases (4.8\%) LSIL (fig: 1a) and 6 cases $(2.6 \%)$ as HSIL (fig: $1 \mathrm{~b}$ ) and $6(2.6 \%)$ were ASCUS. High percentage of smears were inflammatory (88.3\%). Table I

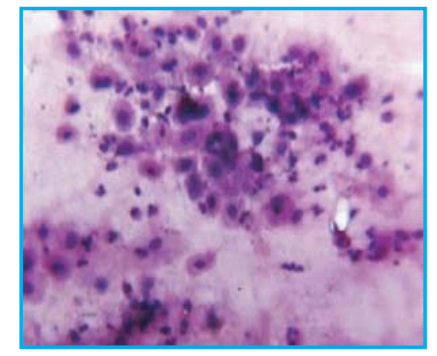

Fig: (1a) Pap smear with cytological features suggestive of a (LSIL)

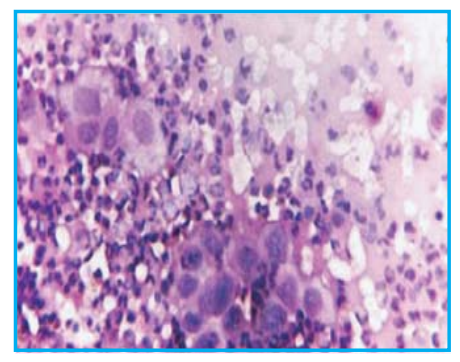

Fig: (1b) Pap smear with cytological features suggestive of a (HSIL)
Table I: Distribution of cytological pattern of various lesions

$\begin{array}{llll}\text { Total Case } & \text { Normal } & \text { Inflammatory } & \text { SIL } \\ 230 & 4(1.7 \%) & 204(88.3 \%) & 22(10 \%)\end{array}$

Cervical squamous intra epithelial lesions (SIL)

$\begin{array}{lll}\text { LSIL } & \text { HSIL } & \text { ASCUS } \\ 10(4.8 \%) & 6(2.6 \%) & 6(2.6 \%) .\end{array}$

In table II Trichomonas infection- 33 (74.5\%), Candida albicans11 (24.86\%). Incidence of Trichomonas infection and Candida albicans in cervical squamous intraepithelial lesion were $3.3 \%$ and $0.66 \%$ respectfully.

Table II : Distribution of different types of pathogens and associated with SIL: (Ref. fig. 2a \& 2b)

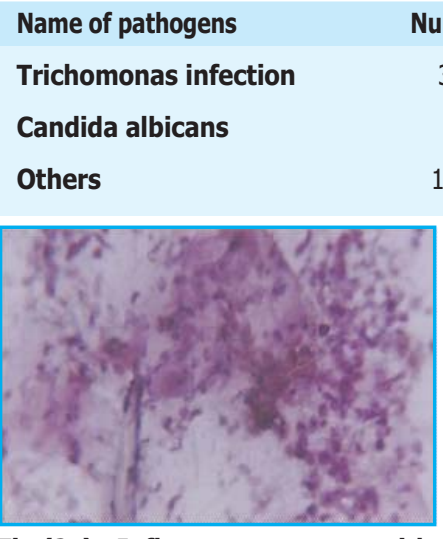

Fig (2a) : Inflammatory smear with budding yeast and hyphae of Trichomonasvaginalis

$\begin{array}{cc}\text { Number of cases } & \text { Incidence of SIL } \\ 33(16.17 \%) & 10(3.3 \%) \\ 11(5.40 \%) & 6(0.66 \%) \\ 160(78.43 \%) & 6(9.6 \%)\end{array}$

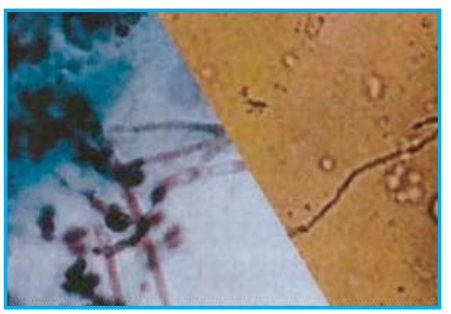

Fig (2b) : Inflammatory smear with vegetative form of candida albicans
Age distribution showed the cervical squamous intraepithelial lesions (SIL) rate showed rise with increasing age (Table III).

Table III : Age distribution of cases

$\begin{array}{ccc}\text { Age group (in years) } & \text { Total no. of cases } & \text { Percentage } \\ 15-25 & 2 & 9.09 \% \\ 26-35 & 6 & 27.28 \% \\ 36-45 & 14 & 63.63 \%\end{array}$

In this study in 36-45 years age group Trichomonas infection was $63.63 \%$ and Candida albicans infection was $54.54 \%$. Both the infection were highest in all age groups (Table IV).

Table IV: Age group distribution of (SIL) with associate infection.

$\begin{array}{lcccc}\begin{array}{l}\text { Age group } \\ \text { (in years) }\end{array} & \begin{array}{c}\text { Trichomonas } \\ \text { infection }\end{array} & \text { Percentage } & \begin{array}{c}\text { Candida } \\ \text { albicans }\end{array} & \text { Percentage } \\ 15-25 & 4 & 12.2 \% & 2 & 18.10 \% \\ 26-35 & 8 & 24.24 \% & 3 & 27.20 \% \\ 36-45 & 21 & 63.63 \% & 6 & 54.54 \%\end{array}$

\section{Discussion}

In the present study Pap smears of 230 women having leucorrhoea are collected from gynaecology O.P.D at Popular medical college hospital. The cases belonged to different age groups in reproductive life with a complaint of vaginal discharge. The cytological evaluation revealed as maximum number of inflammatory smears $204(88.3 \%)$, SIL's were found in 22 cases $(10 \%)$. cases. This result was consistent to the work done by 
Pairwuti S, Dept. of Obstetrics and gynaecology, Siriraj hospital, Mahidol University Bangkok, Thailand in June $1990^{6}$. In this present investigation incidence of Trichomonas infection was 33 (16.17\%) followed by candida was $11(5.40 \%)$ cases. Similar result was found in the work done by Viswanath and Talwar on Syndromic management of vaginal discharge among women in a reproductive health clinic in India ${ }^{7}$

In the current study inflammatory lesion was found in $88.3 \%$ and LSIL-4.8\%, HSIL-2.6\%, ASCUS-2.6\%. The result was comparable to the work done by the Yogita M. Patel et al that inflammatory lesions- $47 \%$ and SIL- $10.5 \%{ }^{8}$ and also with some other authors work ${ }^{9-11}$. As the reproductive age group were taken in the study out of 230 cases 204 cases showed nonspecific inflammation. Cytology revealed that LSIL and HSIL are more common in the age group of 35 years and above. The incidence of SIL associated with Trichomonas and Candida infection showed rise with increasing age group.

\section{Conclusions}

Considering the findings of the present study it can be concluded that cytological evaluation revealed maximum number of inflammatory smears followed by SIL's and common inflammation were associated with Trichomonas infection followed by Candida infection. As (SIL) have long course to turn into invasive stage.

\section{References}

1. MisraJ.S.Daszk and Harish A cytological studies in women complaining of leucorrhoea. Journal of cytology. 14(1):11,1997.

2. National institutes of health. Cervical Cancer. NIH Consensus satetment.1996;14(1):1-38. U.S Cancer statistics working group. United States Cancer Statistics: 1999-2011. Incidence and Mortality Web;based report.
3. The 1998 Bethesda system for reporting cervical/vaginal cytologic diagnosis. Developed and approved at the national cancer institute workshop in Bethesda, Maryland, Dec. 12-13,1988: HUMAN PATHOLOGY, Vol. 21, No. 7,(July 1990); 704-708.

4. Bray F, Ren JS, Masuyer,Ferlay J(2013). Global estimates of cancer prevalence for 27sites in the adult population in 2008. Int I Cancer,132(5): 1133-1145.

5. Harvey M. Cramer, and Suzanne: Cytomorphologic correlates of Human Papiloma Virus infection in the Normal cervico vaginal smear: ActaCytologica Vol.41,No.2/Mar 1997;261-268.

6. Pair wuti S. department of Obstetrics \&Gynaecology, Faculty of Medicine, Siriraj Hospital, Mahidol University, Bangkok, Thailand: Pap smear examinationof women at the out-patient department of Siriraj Hospital: J Med Assoc Thai 1990 Sep;73(9);473-8.

7. Viswanath S, Talwar V, Prasad R, Coyajik, Elias CJ, de Zoysa I, Department of Microbiology, University College of medical Sciences, New Delhi, India: Syndromic management of vaginal discharge among women in a reproductive health clinic in India: Sex Transm infect 2000 Aug, 76(4):303-6.

8. Yogita.M.Patil, R.N.Consai. Pap smear study of cervical cytology. Int J Sceintific Research.425,426, Vol:3,issue 11, Nov 2014. ISSN no 2277-8179.

9. Deodhar L, Karnad J. Department of Microbiology, lokmanyaTilak Municipal Medical college, Bombay: Invitro adhesiveness of GardnerellaVaginalis Strains in relation to the occurance of clue cells in Vaginal discharge: Indian J.Med Res 1994 August,100;59-61.

10. Rewari N, Chadha P and Kriplani A Department of Obstetrics and Gynaecology, MAMC Hospital New Delhi: Microbiological Study of vaginal discharge associated with the use of cu T 200: J.Indian Med Assoc 1991 Oct, 1989(10);289-91.

11. Sanchaz SE, Koutsky and Fernandez A. Department of Epidemiology, University of Washington, Seattle 98109, U.S.A.: Rapid ad inexpensive approaches to managing abnormal vaginal discharge or lower abdominal pain, and evaluation in women attending gynaecology and family planning clinics in peru: Sex Transm infect 1998 June, 74 suppl 1:585-94. 